\title{
EPIDEMIOLOGY AND CONTROL
}

The Fifth International Congress of Leprosy, held in Havana in I948, dealt in detail with the subjects of epidemiology and control of leprosy in the light of knowledge existing at that time. The present report gives emphasis to certain new facts which have been brought to light in the past five years, namely:

I. The influence that the medicaments have with respect to control.

2. The promising results which have recently been obtained with the lepromin reaction induced by B.C.G. 


\section{EPIIDMiol.o(iY}

The Committee emphasizes, for those countries with endemic leprosy, the importance of obtaining more extensive data on the prevalence of the disease. The determination of prevalence, in highly populated countries, is to be accomplished by means of surveys, which should meet the following conditions:

(a) The groups studied should be relatively large, and carefully selected;

(b) Consideration should be given to the socio-economic and climatic factors, and to others including race, sex, and age.

(c) The proportions of the types and groups among the cases encountered should be determined.

To determine the trend of disease, such surveys should be made as frequently as possible, the intervals not exceeding ten years.

We emphasize the concept that the evaluation of control measures should be based on the results of such epidemiological studies.

\section{CONTROL}

The modern anti-leprosy campaign is based upon the following points:

I. Education and bealth propaganda:

(a) The training of leprologists by means of special courses of instruction.

(b) The training of health officers, who should participate, in every way possible, in the campaign against leprosy.

(c) The instruction of general practitioners.

(d) The introduction or development in the curricula of medical schools of adequate courses of instruction in modern leprology.

(e) The proper preparation of auxiliary health personnel.

(f) Health propaganda, which should be carried out by specialized organizations having as their ultimate aim the discovery, as completely as possible, of the cases of the indeterminate group, which form the matrix of the endemic condition.

2. Protection and control of contracts:

A. Protection:

(a) Induction of lepromin reactivity by means of B.C.G. ${ }^{1}$

$i$ The (ieneral Council of the Congress proposed that this sentence be struck out, holding that the use of B.C.G. is still in the experimental stage and that as yet there is no adequate evidence to justify the indicated view that it is an established measure of prophylaxis. The final plenary session, however, voted for the retention of the statement. 
(b) Preventive treatment of contacts beyond the age of ten years who remain lepromin negative in spite of B.C.G. vaccination. The possibility of applying this measure to children of younger age should be considered.

B. Control:

This should be effected with the following orientation:

(a) Lepromin-positive contacts of indeterminate and quiescent tuberculoid cases do not require surveillance.

(b) Lepromin-positive contacts of lepromatous cases require periodical, although not frequent, surveillance.

(c) Lepromin-negative contacts should be observed periodically, as frequently as possible.

3. Ont-patient treatment of tuberculoid and indeterminate cases, and also lepromatous cases presenting few lesions with scanty bacilli, and which are susceptible of being made negative within a short period of time.

4. Selective isolation of contagious cases. The period of hospitalization should be sufficiently long to obtain clinical regression and bacteriological negativization in examinations made periodically, taking into account the conditions prevailing in each country. Once this has been achieved, the patient can be transferred to a dispensary, where he will continue to be under regular observation and treatment.

5. Scientific investigation: This activity is of special importance because of the knowledge to be derived from it regarding the prevalence and incidence and the methods of control.

6. Social assistance: This should include the material and moral assistance to the children and other relatives of the patients, until he is completely rehabilitated and able to return to his work.

To accomplish these objectives of the modern anti-leprosy campaign, the following institutions should be provided:

I. Sanitarium: This institution should have as its principal objective the recovery of the physical and moral health of the patients in the broadest sense of the term.

2. Urban or transient hospital: Such a hospital may function either as an independent unit, or as an auxiliary of the dispensary or of a general hospital.

3. Dispensary: This entity should play a preponderant and dynamic role among the agencies of the anti-leprosy campaign. There should, therefore, be an adequate number of well-equipped dispensaries to carry out the following activities: 
(a) Health education and propaganda.

(b) Protection and control of contracts.

(c) Discovery of new cases, with special attention to those of the indeterminate group because of their possible evolution to the lepromatous type.

(d) Treatments of patients and contacts according to standards previously stated.

(e) Selection of the cases which should be hospitalized.

(f) Training of technical personnel.

(g) The carrying out of epidemiological investigations.

4. Preventorium: This should also be an active organization, the primary aim of which is the removal of children from infectious environment. Its technical activities should be carried out in accord with the following points:

(a) Children in contact with lepromatous cases, who are lepromin negative, should be given priority for admission.

(b) The interned children should be subject to close observation, especially those which are lepromin negative.

(c) Induction of lepromin reactivity by means of B.C.G. should be practiced, and preventive treatment should be given to those who remain lepromin negative.

(d) Reintegration into society of the children who have completed their periods of observation, which should be as short as possible. If necessary, observation should be continued by social service organizations.

(e) Education of the interned children, which should be carried out preferably by institutions, public or private, located outside the preventorium in order that their future reintegration in society may be facilitated.

5. Research institution: Such institutions, adequately supported, should be provided to study the disease with respect to its epidemiology, prevention and treatment.

\section{RECOMMENDATIONS}

I. Because of the efficacy of the new medicaments, it is reasonable to assume that these drugs will reduce considerably the period of contagiosity of the lepromatous cases. To investigate this matter, which we regard as of great importance, extensive investigations should be carried out in countries where institutional isolation is impracticable, with the aim of determining if there is any reduction of the incidence of leprosy among the contacts of lepromatous cases. 
2. The Committee recommends that B.C.G. vaccination be introduced in the prophylaxis campaigns. It also recommends that adequate studies be carried out, under the most varied conditions, to determine the exact value of this measure and of the induction of lepromin reactivity by B.C.G. It would be of value to compare the possible differences of the protective effect of B.C.G. vaccination among contacts who are removed from infectious environments and among those who are not separated.

3. The Committee recommends that the public health services of the different countries send, periodically, to the World Health Organization information concerning the prevalence of leprosy. The Committee reaffirms that leprosy belongs to the group of infectious and contagious diseases, and that consequently definite measures of control should be employed when dealing with it.

4. The Committee, having in mind the advances made with the new medications, recommends the revision of existing legislation in the different countries. This should comprise the modern basis of control and social assistance, as set forth above.

5. It is recommended that the children of leprosy patients separated immediately after birth should, by preference, be placed with families, or institutions, public or private, which are designed for the protection of infants in general, and not in preventoria for leprosy contacts. 